\title{
Foreword
}

\section{Welcome to the Special Section on ITE Awards Selection}

\author{
Editor-in-Chief Yukinobu Taniguchi
}

The Institute of Image Information and Television Engineers (ITE) acts to promote research and development in the field of image information and television, and to contribute to their progress in Japan and around the world. Annually, the ITE commends persons and groups who have made great achievements in the technology of image information and television. The awards include the Niwa \& Takayanagi Award (Distinguished Services Award, Achievement Award, and Excellent Paper Award), Technical Progress Award (Progress \& Development Award and Contents Technical Award), Fujio Frontier Award, Hi-Vision \& Next-generation TV Technical Award, Suzuki Memorial Achievement Award, and Best Research Presentation Award.

The ITE considers it valuable to introduce awarded technologies to the community that is actively involved in the research and development of media technology and applications, and invite paper submissions from winners of the Technical Progress Award, Fujio Frontier Awards, and Hi-Vision and Next-generation TV Technical Award, which deal with leading-edge technology. Eight papers were submitted to the Transactions on the Media Technology and Applications (MTA) and the ITE Journal (https://www.jstage.jst.go.jp/browse/itej/-char/ja/), which is for papers written in Japanese. The papers were carefully reviewed and accepted by the ITE Journal editorial committee.members.

In this special section, we present a paper entitled "Free-viewpoint Video Synthesis for Sport Scenes Captured with a Single Moving Camera" by Hiroshi SANKOH, Sei NAITO, Mitsuru HARADA, Toshiharu SAKATA, and Michihiko MINOH from Free-Viewpoint Video R\&D team, who was awarded the Technical Progress Award 2013. The paper describes the technical detail on free-viewpoint video synthesis.

I hope that readers will be interested in the technology and, this special section will promote further advancement of research and development in media technology and applications. 